\title{
Filosofía de la biología y de la técnica*
}

Philosophy of Biology and Philosophy of Technique

Jaime Fisher ${ }^{\dagger}$

\section{Resumen}

Asumo aquí una posición que apenas necesita defensa entre naturalistas: el continuum entre biología y cultura. Intento llamar la atención, por un lado, sobre las bases biológicas de la técnica y su evolución recíproca; y, por otro, sobre las bases técnicas de la biología y la evolución mutua entre biología y técnica. Esto puede ser fértil en la tarea de pensar qué es el hombre y qué puede ser mediante su hacer en el mundo. Implicaría, más que un mero acercamiento, un mestizaje entre biología y antropología, y, por ello, entre filosofía de la biología y filosofía de la técnica.

Palabras clave: evolución - transacción - técnica - adaptabilidad

\begin{abstract}
My initial stance scarcely needs a defense among naturalists: the continuum between biology and culture. From there I try to call attention, on one hand, to the biological basis of the technical and their reciprocal evolution; and, on the other, over the technical basis of biology and the mutual evolution between biology and techniques. This approach could help us advance in the task of understanding what humanity is and can become through its action upon the world. I envisage a picture that goes beyond a mere approximation, and involves a real intermingling of biology and anthropology and therefore of philosophy of biology and philosophy of technique.
\end{abstract}

Keywords: evolution - transaction - technique - fitness

\footnotetext{
* Recibido: 1 de Febrero de 2016. Aceptado con revisiones: 5 de Diciembre de 2016.

† Departamento de Filosofía, Universidad Veracruzana. Para contactar al autor, por favor, escribir a: jaime.fisher@gmail.com. Metatheoria 8(2)(2018): 53-61. ISSN 1853-2322.

(c) Editorial de la Universidad Nacional de Tres de Febrero. Publicado en la República Argentina.
} 


\section{Evolución: biología y técnica}

Existe un amplio consenso en torno a la idea de que nadie puede ser naturalista en filosofía sin considerar los resultados de la ciencia. ${ }^{1}$ No se puede ser naturalista en particular sin considerar los resultados de la biología y su paradigma: la teoría de la evolución por selección natural. La primera consecuencia lógica de esto para una filosofía naturalista de la técnica es que no puede llevar a cabo su labor sin considerar las bases biológicas de la cultura, pues ahí es donde la técnica adquiere su función más destacada y, por ello, donde cobraría su principal interés filosófico. Puede afirmarse incluso que no habría cultura sin técnica, cosa que implicaría considerar a la filosofía de la cultura como una rama de la filosofía de la técnica, ${ }^{2}$ aunque argumentar en respaldo de esto último ocuparía más espacio del disponible. Por otro lado, el naturalismo conduce a mirar la otra cara de la moneda: la biología y la filosofía de la biología podrían beneficiarse del intercambio con algunos de los resultados más relevantes obtenidos en la reflexión filosófica sobre la técnica, y en particular con eso que llamaré aquí las bases técnicas de la evolución biológica.

Si bien hubo intentos por vincular objeto y método de las ciencias sociales con las raíces biológicas de la conducta humana, particularmente en Inglaterra durante la primera mitad del siglo pasado (Renwick 2012), fue sólo tras la publicación del conocido y polémico texto de Wilson (1975) que esas disciplinas volvieron la vista hacia la biología, aunque haya sido casi sólo para intentar refutar las presuntas conclusiones de Wilson. ${ }^{3}$ Pese a la turbulencia que provocó y aun provoca entre sociólogos, antropólogos e incluso entre filósofos naturalistas, considero que estableció con claridad las bases biológicas de la conducta humana, ${ }^{4}$ y, con ello, las bases biológicas de la técnica (Wilson 1998, 2004 [1978]). Casi en imagen especular, hoy existe escaso interés en biólogos y filósofos de la biología respecto al peso que las variables técnicas y culturales han tenido y están teniendo sobre los mecanismos de variación y selección biológica, y de la especie humana en particular. Es por ello sugerente intentar suplementar esto y transitar el camino en sentido inverso, considerando las bases técnicas de la evolución biológica.

\section{Dos razones en filosofía de la biología para considerar la filosofía de la técnica}

El ser humano vive en y a través de lo que Stephen Clark (2003), entre otros, llama tecnosfera. El término refiere a un medio ambiente cada vez más poblado y constituido por artefactos físicos y simbólico-culturales, en gran medida asociados de forma causal con el desenvolvimiento científico. Dada la teoría de la evolución, biólogos y filósofos de la biología tienen buenas razones para tomar en cuenta la técnica y su filosofía si consideramos dos hechos.

El primero es de carácter epistemológico y metodológico: como ciencia experimental, el avance del conocimiento en biología depende del desarrollo de nuevos y más potentes instrumentos capaces de arrojar luz sobre los procesos característicos de los seres vivos. Igual que otras ciencias empíricas, la biología depende de la observación y experimentación tecnológicamente mediadas, cosa evidente en biología molecular, en neurociencias y en ciencias cognitivas, entre otras. El segundo punto de vista que aquí resulta más importante- es de orden ontológico: el desenvolvimiento de la técnica ha

\footnotetext{
${ }^{1}$ Sin embargo, entre naturalistas es posible hallar un amplio abanico a veces difícil de caracterizar como consenso. Un ejemplo de ello puede hallarse en Bashour y Muller (2014).

2 Por técnica entiendo una acción sistemática conducida por un saber cómo, es decir, un conocimiento de las relaciones entre la acción y sus resultados; mientras que por tecnología se entiende una técnica de base científica, es decir, un saber cómo sostenido en un saber por qué. Toda tecnología es una técnica, pero no se cumple la inversa.

3 Sociobiología, como suele ocurrir con otros textos, ha sido más citado y comentado que leído. Hay autores (Sahlins [1976] 1982, Lewontin 1992, Feldman 2003) que le imputan un determinismo genético que no aparece en ninguna de las dos versiones (la original y la abreviada). Críticas posteriores pasan por alto lo escrito junto a Lumsden (Lumsden \&. Wilson 1981).

${ }^{4}$ Con este subtítulo se publicó, apenas un año después del de Wilson, otro de Richard Dawkins (1976). Es requerido un trabajo historiográfico sobre el papel que ambos tuvieron -junto a los seminales textos de Grene (1974) y Hull (1974)- en el acelerado impulso que cobra la filosofía de la biología durante esa década.
} 
cambiado, y está cambiando de manera acelerada, ese medio ambiente biocultural, o tecnosfera, transacción ${ }^{5}$ en la cual tiene lugar y cobra sentido la evolución misma de los organismos y los grupos, incluyendo por supuesto al hombre. Parafraseando la idea de Kuhn (1962) de acuerdo con la cual el científico -tras un cambio de paradigma- vive en un mundo ontológicamente distinto, ${ }^{6}$ puede afirmarse que tras un cambio técnico el hombre vive en un mundo biológicamente distinto. Si esta paráfrasis tiene sentido -y lo tiene-, entonces se justifica y requiere que la biología y la filosofía de la biología atiendan al desenvolvimiento de la tecnología y de la filosofía de la técnica.

La ontología distinta a que se refiere Kuhn en realidad tiene que ver más con la epistemología. Para utilizar el término de Peter Geach (1969), un cambio de paradigma sería una especie de Cambridge change, ese que ocurre por el simple cambio en la perspectiva o la intencionalidad de un agente. Como éste está en el mundo entonces el mundo cambia cuando cambia la perspectiva o los meros estados mentales del sujeto, cosa verdadera pero trivial. No se afirma que estos cambios no importen en filosofía, y en particular en epistemología, pero sí que en filosofía de la técnica y de la biología más importan los cambios que ocurren en el mundo externo que los que ocurren en nuestro punto de vista o en nuestra intencionalidad. Más aún: tanto en biología como en la técnica, los cambios epistemológicos tienen como condición de posibilidad cambios ontológicos, e.e., la evolución misma del sistema nervioso y del cerebro en transacción con su medio ambiente.

Bien, pues la técnica no sólo cambia la percepción que tenemos sobre el mundo, no sólo en lo cognoscitivo o lo epistemológico, sino en el mismo mobiliario del mundo; y, lo más importante aquí: está cambiando los fenómenos de lo vivo que constituyen la ontología propia de la biología como ciencia empírica. Por este proceso más fundamental viene a colación Kuhn: tras un cambio técnico el hombre vive en un mundo biológicamente distinto porque tal cambio técnico cambia la tecnosfera, ese medio ambiente cada vez más complejo y responsable de la selección -y según algunos autores ${ }^{7}$ también de la variación- en el proceso evolutivo.

Los cambios en la tecnosfera amplían o reducen el rango de adaptabilidad. Un ejemplo (intencional) de lo primero es la medicina y la higiene: sin las técnicas farmacológicas e higiénicas desarrolladas hasta hoy una buena parte de la humanidad ya hubiera desaparecido; otra parte ni siquiera hubiera tenido oportunidad de vivir. Un ejemplo (no intencional) de lo segundo es el efecto invernadero asociado al consumo de combustibles fósiles. Si, desde el punto de vista de la larga data evolutiva, estas aplicaciones técnicas producen o no una variación genética heredable no estamos en condiciones de ofrecer una respuesta clara, pues la variación-especiación es fenómeno que, por su naturaleza, no resulta observable en un sentido experimental fuerte. No obstante, sí es observable que la técnica produce una mayor adaptabilidad (o inadaptabilidad), tanto entre las especies como entre distintos individuos dentro de una misma especie, y la tecnosfera aparece como ese espacio en que se modifica de manera cada vez más significativa al mecanismo de selección, mismo que deja de ser natural y comienza a ser cada vez más artificial, más técnico. El mecanismo de selección natural, pues, opera en forma creciente a través de la técnica y la cultura. Estos serían dos hechos y razones para que la filosofía de la biología integre en su reflexión a la filosofía de la técnica.

\footnotetext{
${ }^{5}$ El concepto de transacción desarrollado por Dewey (1896), influenciado por Darwin desde 1896, es fundamental para entender tanto la relación entre medio ambiente y organismo como entre biología y técnica. Las referencias a Dewey aquí listadas son fuente donde hallar una idea adecuada y completa del concepto.

${ }^{6}$ Aunque esta idea es una constante que atraviesa el texto, es en el capítulo X, "Revolutions as Changes of World View" (pp. 111-135), donde alcanza mayor claridad.

${ }^{7}$ Jablonka y Lamb (1995), Newman y Bhat (2011).
} 


\section{Dos caminos de la filosofía de la biología hacia la filosofía de la técnica}

Cabe también apuntar al menos dos vertientes de reflexión principales a través de las que la filosofía de la biología debería considerar a la técnica y a la filosofía de la técnica.

La primera, más evidente y dirigida hacia el futuro, consiste en el desarrollo reciente de la ingeniería genética y la biología sintética, así como otros desarrollos aún en fase teórica pero que se prevé pronto estarán disponibles, como la nanotecnología o los implantes computacionales, temas que pueden ser agrupados en el llamado transhumanismo. ${ }^{8}$ Entre los problemas fundamentales que esto le presenta a la filosofía de la biología destaca que la biología sintética, como técnica, eliminaría o por lo menos reduciría el carácter aleatorio del mecanismo de variación; las implicaciones morales y políticas son obvias, aunque demasiado extensas y peliagudas para tratarse aquí. ${ }^{9}$ La segunda vertiente de reflexión -más importante para las intenciones de este artículo-, se asocia al segundo fenómeno apuntado en el apartado anterior, se dirige al pasado lejano, y se constituiría en estrecho vínculo con diversas ciencias empíricas, en particular con la antropología física y social, la paleontología y la biología molecular. Tiene que ver con el cómo y en qué medida la mismísima evolución del Homo sapiens - a partir de alguna especie de Australopithecus- ha sido un producto conjunto del medio ambiente y de la técnica, ${ }^{10}$ que es teleológica y, por ello, no totalmente azarosa; aunque, desde luego, nadie supone que el proceso como un todo sea intencional. Lo que sostengo es la simple y constatada existencia de consecuencias no intencionales de la acción intencional, individual y colectiva, sobre el mecanismo global de selección. Parecería por ello razonable que la reflexión de los filósofos de la biología considerase dentro de su propia labor, en forma más sistemática y profunda, a la técnica y a las reflexiones filosóficas sobre ella.

\section{Una asimetría que requiere atención}

Aunque biólogos y filósofos de la biología no suelen considerar en su trabajo las ideas filosóficas generales sobre la técnica, sí utilizan en sus propias reflexiones -con comodidad y profusión- el lenguaje teleológico y funcional propio de la filosofía de la técnica. ${ }^{11}$ Por su parte, en filosofía de la técnica algunos autores han sido y son reticentes a utilizar las analogías provenientes de la biología y la filosofía de la biología, en particular la de la evolución. ${ }^{12}$ Estas reticencias, no siempre ayunas de razón, se organizan en torno al argumento según el cual el mundo técnico-cultural es un proceso mediado por la intencionalidad, mientras que el mundo biológico-evolutivo, por su lado, sería más bien un proceso azaroso y ciego.

Tal asimetría puede corregirse, por un lado, mediante una biologización de la filosofía de la técnica. El propio Darwin ([1876] 2009) abre la puerta para legitimar la intención de vincular ambos campos y eliminar -o al menos disminuir- la brecha señalada:

\footnotetext{
8 Véase Diéguez (2017). Jablonka y Lamb (2014, pp. 60-91) son escépticos al respecto, tanto por la complejidad de un eventual diseño genético preciso, como porque existen otras dimensiones de la evolución: no todo está en los genes, sino también en el medio ambiente físico, simbólico, técnico, cultural, de manera que: "We should also consider nongenetic transmissible factors" (p. 75).

9 Véase Carlson (2010) y el número monográfico de Issues in Science and Technology, Volume XXXII, Issue 3, Spring 2016, University of Texas at Dallas.

${ }^{10}$ Esta idea no está ayuna de objeciones. Autores clásicos de la talla de Lewis Mumford ([1967] 2010) opinan que sobreestima el papel de la técnica en la evolución humana. Tal vez quien más sobreestimó ese papel haya sido Engels ([1876] 1980). Mi posición es que si no se debe sobreestimar, menos aún se puede ignorar el papel que la técnica tuvo y tiene en la evolución humana. En el siguiente apartado se propone un punto de equilibrio y una línea de reflexión similar a la sugerida por Nelson (2007).

11 "Biology is unique among the natural sciences in its use of a family of concepts that might seem better suited to the description and explanation of artifacts than the description and explanation of organisms" (Lewens 2004, p. 14).

${ }^{12}$ Cabe destacar entre ellos -aunque a cada uno por distintas razones- a Ellul (1990), Sachs (1992), Dessauer (1964), el citado Mumford, Shiva (1995) y Norberg-Hodge (1995). Por el contrario, Dawkins (1976), Lumsden \& Wilson (1981), Sahal (1981), Dosi (1982), Dennett (1995), Aunger (2002), Cavalli-Sforza (2007), entre otros, sugieren una darwinización de la técnica y la cultura. Un caso que ilustra el abanico de dudas razonables entre una posición y la otra es el de Richard Nelson (2007). Basalla (1988) es quizá el autor más evolucionista en filosofía de la técnica, mientras que Richerson y Boyd (2005) son más radicales: parafraseando a Dobzhansky sostienen que nada en la cultura tiene sentido excepto a la luz de la teoría de la evolución (1976, cap. 7, p. 237 y ss.)
} 
Almost every part of every organic being is so beautifully related to its complex conditions of life that it seems as improbable that any part should have been suddenly produced perfect, as that a complex machine should have been invented by man in a perfect state (pp. 33-34, énfasis añadido).

En este párrafo se instila la idea de proceso y cambio gradual, tanto en los organismos como en los artefactos. La ceguera del relojero no parece distinta a las conjeturas y refutaciones en la ciencia, y a su correlato en la técnica y la cultura. Si consideramos la historia de la ciencia y la tecnología, la diferencia entre ceguera biológico-genética e intencionalidad técnico-cultural sólo es una diferencia de grado. Esto no implica que la diferencia no importe: sólo establece que la naturaleza ensaya variaciones que resultan exitosas o no con relación a un determinado medio ambiente; y que la técnica también ensaya variaciones que, no obstante su intencionalidad, tampoco tienen asegurada su supervivencia en la tecnosfera. Algunos de estos ensayos técnicos son barridos por lo que, en analogía, podemos llamar selección cultural, o selección técnica. Otros logran sobrevivir, y evolucionan por senderos a lo largo de los cuales siguen siendo sometidos a esa constante criba, a veces entendida como selección o construcción social. ${ }^{13}$

Sostengo, pues, que la selección natural opera a través de la selección técnica: los organismos que de manera pertinaz son incapaces de hacer lo adecuado o eficiente (fitness) en relación a su medio ambiente tienden a desaparecer; y de aquí que, de manera complementaria, una mayor tecnificación en filosofía de la biología sea también razonable. ${ }^{14}$ La variación metodológica se justifica y requiere en las dos áreas, y permitiría una reducción en la brecha arriba mencionada.

Con la tecnificación de biología y filosofía de la biología no sólo defiendo la validez del uso del lenguaje teleológico y funcional en esas disciplinas, sino algo más fuerte relacionado con ese uso, a saber, que si es posible, razonable y útil la metáfora técnica intencional ahí es porque en la naturaleza existe la finalidad; porque ahí, en la naturaleza, hay teleología, hay fines; y de ahí que las metáforas y analogías funcionales y teleológicas resulten descripciones epistemológica y fenoménicamente adecuadas - por lo menos en y para la escala humana-, de los procesos biológicos (Grene 1974, ${ }^{15}$ Lewens 2004, ${ }^{16}$ Richerson \& Boyd 2005, ${ }^{17}$ Carlson 2010). ${ }^{18}$ Por supuesto, esto es más fácil decirlo que probarlo, pero la tesis, en caso de resultar sostenible, no abriría la puerta al diseño inteligente; sólo afirma que los seres vivos tienen el fin o la intención de perseverar en su ser, y que, si lo consiguen o no, ese seguirá siendo un problema biológico y técnico (biotécnico). El proceso de variación-selecciónderiva-especiación-sobrevivencia cruza por la eficiencia técnica. La evolución de organismos vivos y sistemas técnicos estaría sometida al mismo tipo de presión selectiva.

Que haya variaciones ciegas o aleatorias en la técnica (Dewey 1952[1929], Simondon, 2007); ${ }^{19}$ y, de manera paralela, que existan funciones técnicas intencionales en los organismos, e incluso variaciones genéticas no totalmente azarosas (Jablonka \& Lamb 2014), es lo que permite y requiere el uso del lenguaje teleológico en biología y del lenguaje evolutivo en la técnica. Desde el punto de vista de la

\footnotetext{
${ }^{13}$ Hughes (2012).

${ }^{14}$ Jablonka y Lamb $(2014$, p. 93) argumentan que "There is now good experimental evidence, as well as theoretical reasons, for thinking that the generation of mutations and other types of genetic variation is not a totally unregulated process" (énfasis añadido). Desde un punto de vista lógico, esto abre la puerta a cierta direccionalidad en biología, pues si no todo es mera lotería genética entonces cabría una respuesta técnica no sólo del organismo, sino incluso del DNA, frente a la presión del medio ambiente.

${ }^{15}$ En particular el capítulo IX, "Biology and Teleology" (pp. 172-179).

${ }^{16}$ Partiendo de la analogía organismo-artefacto argumenta en favor del enfoque evolutivo tanto en biología como en la técnica.

17 Invierten la relación sugerida por Wilson y Dawkins, y exponen las bases técnico-culturales de la evolución humana.

${ }^{18}$ Defiende que la biología es tecnología, en el sentido en que se entiende aquí técnica.

19 Dada la repulsión de Simondon por el pragmatismo, citarlo junto a Dewey parece inadecuado. Creo que Simondon tiene más coincidencias con el pragmatismo de lo que él mismo se permite reconocer; algo similar ocurre con Ortega; aunque eso sería motivo de otro ensayo.
} 
teoría de la acción muy cercano al sostenido por Dennett $(1987),{ }^{20}$ las analogías funcionan en la descripción y búsqueda de explicaciones de los fenómenos en ambos campos.

La idea se basa en evidencia empírica: todo ser vivo tiene la intención de mantenerse vivo; y para lograrlo ha de resolver diversos problemas que le presenta su entorno. Esto constituye un problema biotécnico: actuar ante ciertos estímulos de determinada manera, o no hacerlo, suele establecer la diferencia entre ser barridos o no por la selección natural. Los biológicamente más aptos son, desde el punto de vista de la teoría de la acción, los técnicamente más eficientes. Por supuesto, la eficiencia biológica es conseguida -cuando lo es- solo después de múltiples variaciones fallidas, cuya evidencia está en el registro fósil. La eficiencia técnica es conseguida -cuando lo es- también sólo tras múltiples intentos fallidos en el diseño, construcción y uso de artefactos y sistemas técnicos, cuya evidencia está en la historia de la técnica. ${ }^{21}$ Que en este último caso el proceso de corrección-adaptación sea más rápido no introduce una diferencia de fondo respecto al proceso y tiempo que toma al relojero ciego realizar su labor en la biología. Esto, pues, no daría intenciones a un diseñador global, sino sólo a los organismos y sistemas técnico-culturales que co-evolucionan (Lumsden \& Wilson 1981) a través de un medio ambiente que los somete a constantes presiones genéticas, epigenéticas, conductuales y simbólico-culturales (Jablonka \& Lamb 2014)

\section{Una visión desde el naturalismo pragmatista}

John Dewey ([1925] 1948) - muy influenciado por Darwin- propone a la experiencia como unidad de evolución. La entiende como una transacción en la naturaleza, de la naturaleza, acerca de la naturaleza y a través de la naturaleza. Tal experiencia sería técnica en un sentido básico, puesto que la transacción medio ambiente-organismo implica que este último hace o evita hacer algo para intentar mantenerse vivo y dejar descendencia.

Así como el mecanismo básico de variación genética, el inicio de la técnica también es ciego. Dice Dewey en La busca de la certeza ([1929] 1952):

La historia del progreso humano es la historia de la transformación de sus actos que, como las interacciones de las cosas inanimadas, ocurren sin saber que sean acciones cualificadas por un entendimiento acerca de lo que tratan; es la historia de la transformación de las acciones controladas por las condiciones externas en acciones guiadas por la intención, por la previsión de sus propias consecuencias. La dirección, la información, el conocimiento son los únicos modos con los cuales la inteligencia llega a cualificar actos originalmente ciegos (p. 215, énfasis añadido).

La unidad de evolución, pues, sería la transacción técnica experiencial organismo-medio ambiente, cosa que desde un punto de vista lógico vale tanto para la biología como para los sistemas técnicos. La evolución es el resultado de la complejización creciente en las técnicas de todo organismo para lidiar con el medio en el intento ese de perseverar en su ser, es decir, en la lucha por la supervivencia, fenómeno ubicuo entre los seres vivos.

En el hombre, por supuesto, la supervivencia es sólo condición de posibilidad para la bienvivencia (Ortega y Gasset [1939] 1964). Sin embargo, nada garantiza esto, ni en la biología, ni en la historia, ni en la cultura. Todo depende de qué se haga y qué se omita hacer: no hay determinismo técnico, y el desenvolvimiento de la ciencia y la tecnología muestra que tampoco hay determinismo genético o biológico. Todo depende de la capacidad de la experiencia para transformarse a sí misma e intentar hacer de la vida una obra de arte (ars, techné) (Dewey [1934] 1949).

Al inicio de la evolución biológica y de la aparición técnica se hallaría la misma irritación, un desequilibrio entre el organismo y su ambiente que impulsa al primero a actuar para corregirlo y llevar a cabo acciones intencionales (en el sentido débil de Dennett), dirigidas a recuperar el equilibrio que

\footnotetext{
${ }^{20}$ La estrategia o la actitud intencional de Dennett funciona en etología. Sería un milagro que lo hiciera si no fuera en algún sentido verdadera.

${ }^{21}$ Oakley (1967) vincula la evolución de los artefactos técnicos con la evolución biológica humana mediante la evolución de las habilidades.
} 
pre-existía a la irritación percibida. Tal ajuste es de naturaleza técnica, pues en ambos casos se trata de conseguir, a través de determinados medios, ciertos resultados en lugar de otros, de tal manera que se recupere ese estado de equilibrio, así sea sólo temporal. ${ }^{22}$ Quizá los autores contemporáneos que defienden de manera más amplia, adecuada y firme la visión aquí adoptada, y ya sugerida por Dewey desde principios del siglo pasado (Dewey 1909), sean Adrian Bejan y Peder Zane (2012). ${ }^{23}$

$\mathrm{Si}$ en el agente humano esta conducta técnica es plenamente intencional (presupone libertad, opcionalidad y alternativas en la formación y elección de fines) y en los demás organismos no, es algo que no está claro todavía ni en teoría de la acción ni en etología. Es sólo frente a un problema concreto, entendido como una irritación entre un organismo y sus condiciones ambientales, que se desata un proceso técnico de investigación que produce conocimiento y, por tanto, que sería en este conocimiento, en este saber cómo hacer algo, desde el punto de vista biotécnico, que consiste el proceso de adaptación y, por ello, de sobrevivencia.

Esto hace pertinente para la filosofía de la biología tomar en serio a la técnica, e integrar la reflexión filosófica sobre esta última a su propia labor. Si las variaciones genéticas y epigenéticas tienen que mostrar su adaptabilidad en determinadas características observables de la transacción organismoentorno, entonces tal adaptabilidad puede describirse en términos de la eficiencia técnica observable en esas transacciones. Cabe por ello pensar en la posibilidad y fertilidad heurística que tendría subsumir una parte de la filosofía de la técnica en la filosofía de la biología. Hay, pues, tanto bases biológicas de la conducta técnica (sólo los organismos vivos saben hacer o evitar hacer algo), como hay unas bases técnicas de la evolución biológica (salvo por serendipia, sólo los organismos técnicamente eficientes son capaces de llegar a la edad adulta y dejar descendencia); por ello cabría también subsumir una buena parte de la filosofía de la biología en la filosofía de la técnica. En cualquier caso, la filosofía de la biología y la filosofía de la técnica deberían estar más vinculadas que hasta hoy. Poner esto a consideración de biólogos, filósofos de la biología, ingenieros, antropólogos y filósofos de la técnica puede resultar digno de concitar adhesiones o repulsiones razonables.

Bibliografía

Aunger, R. (2002), The Electric Meme. A New Theory About How We Think, New York: Free Press.

Basalla, G. (1988), The Evolution of Technology, Cambridge: Cambridge University Press.

Bashour, B. y H. Muller (eds.) (2014), Contemporary Philosophical Naturalism and Its Implications, New York: Routledge.

Bejan, A. y P. Zane (2012), Design in Nature, New York-Toronto: Doubleday-Random House, Inc.

Carlson, R. (2010), Biology is Technology, Cambridge: Harvard University Press.

Cavalli-Sforza, L. (2007), La evolución de la cultura, Barcelona: Anagrama.

Clark, S. (2003), From Biosphere to Technosphere, Ends-Means: Aberdeen University.

Darwin, C. ([1876] 2009), The Origin of Species, Cambridge, MA: Cambridge University Press.

\footnotetext{
${ }^{22}$ Hay aquí, desde luego, un problema con intencionalidad y agencialidad. Entiendo intencionalidad como el hecho físico o biológico de tender hacia algo, como cuando la limadura de hierro tiende a reproducir sobre una hoja de papel el campo magnético de un imán; o como cuando un conejo tiende a alejarse de un lugar cuando percibe el olor de un depredador. Por agencialidad entiendo formarse y tener el propósito o la intención plena y consciente de llevar a cabo una determinada acción bajo condiciones de libertad, es decir, bajo condiciones que siempre dejan abierta la posibilidad de realizar esa acción de manera distinta, o de no realizarla en absoluto. Desde luego, cómo se pasa de los meros hechos físicos y biológicos a las acciones conducidas por valores, es asunto que no puede tratarse aquí.

23 "In the big history of life on Earth, the emergence and evolution of inanimate, animate, and technological designs tell a single story. Where Darwin showed the links between biological creatures, the constructal law connects everything on the planet" (Bejan \& Zane 2012, p. 23).
} 
Dawkins, R. (1976), The Selfish Gene, Oxford: Oxford University Press.

Dennett, D. (1987), The Intentional Stance, Cambridge: MIT Press.

Dennett, D. (1995), Darwin's Dangerous Idea: Evolution and the Meanings of Life, London: Penguin.

Dessauer, F. (1964), Discusión sobre la técnica, Madrid: Rialp.

Dewey, J. (1896), “The Reflex Arc Concept in Psychology”, Psychological Review III(July 1896): 357-70.

Dewey, J. (1909), “Darwin's Influence upon Philosophy”, The Popular Science Monthly 75: 90-98.

Dewey, J. ([1925] 1948), La experiencia y la naturaleza, México: Fondo de Cultura Económica.

Dewey, J. ([1934] 1949), El arte como experiencia, México: Fondo de Cultura Económica.

Dewey, J. ([1929] 1952), La busca de la certeza, México: Fondo de Cultura Económica.

Diéguez, A. (2017), Transhumanismo. La búsqueda tecnológica del mejoramiento humano, Barcelona: Herder.

Dosi, G. (1982), “Technological paradigms and technological trajectories”, Research Policy 11: 147-162.

Ellul, J. (1990), The Technological Bluff, Grand Rapids, Mi.: William B. Eerdmans.

Engels, F. ([1876] 1980), "El papel del trabajo en la transformación del mono en hombre”, en Marx y Engels, Obras escogidas, Tomo III, Moscú: Editorial Progreso, pp. 45-56.

Feldman, M. (2003), "Genetics and Behavior”, en Kuper, A. y J. Kuper (eds.), The Social Science Encyclopedia, London: Routledge, pp. 571-574.

Geach, P. (1969), God and the Soul, London: Routledge \& Kegan Paul.

Gissis, S. y E. Jablonka (2011), Transformations of Lamarckism, Cambridge: MIT Press.

Grene, M. (1974), The Understanding of Nature: Essays in the Philosophy of Biology, Dordrecht: Reidel.

Hughes, T. (2012), “The Evolution of Large Technological Systems”, en Bijker, W., Hughes, T. y T. Pinch (eds.), The Social Construction of Technological Systems, Cambridge: MIT Press, pp. 51-82.

Hull, D. (1974), Philosophy of Biological Science, Englewood Cliffs: Prentice-Hall.

Jablonka, E. y M. Lamb (1995), Epigenetic Inheritance and Evolution. The Lamarckian Dimension, Oxford: Oxford University Press.

Jablonka, E. y M. Lamb (2014), Evolution in Four Dimensions, Cambridge: MIT Press.

Kuhn, T. (1962), The Structure of Scientific Revolutions, Chicago: The University of Chicago Press.

Lewens T. (2004), Organisms and Artifacts: Design in Nature and Elsewhere, Cambridge, Mass.: MIT Press.

Lewontin, R. (1992), Biology as Ideology, Toronto: House of Anansi Press.

Lumsden, C. y E. Wilson (1981), Genes, Mind and Culture: The Co-evolutionary Process, Cambridge: Harvard University Press.

Mumford, L. ([1967] 2010), El mito de la máquina. Técnica y evolución humana, Logroño: Pepitas de calabaza.

Nelson, R. (2007), “Universal Darwinism and Evolutionary Social Science”, Biology and Philosophy 22: 73-94.

Newman, A. y R. Bhat (2011), "Lamarck's Dangerous Idea”, en Gissis, S. y E. Jablonka (eds). Transformations of Lamarckism: From Subtle Fluids to Molecular Biology, Cambridge, MA: MIT Press, pp. 157-169.

Norberg-Hodge, H. (1995), “The Pressure to Modernise”, en Goldsmith, E., Khor, M., Norberg-Hodge, H. y V. Shiva (eds.), The Future of the Progress, Guildford, UK: Green Books and The International Society for Ecology and Culture, pp. 91-108.

Oakley, K. (1967), "Skill as a Human Possession”, en Singer, C. y E. Holmyard (eds.), A History of Technology, Vol. I., Oxford: Oxford University Press, pp. 1-37.

Ortega y Gassset, J. ([1939] 1964), Meditación de la técnica. Ensimismamiento y alteración, Madrid: Biblioteca Nueva.

Renwick, C. (2012), British Sociology's lost Biological Roots: A History of Future Past, London-New York: PalgraveMacmillan. 
Richerson, P. y R. Boyd (2005), Not by Genes Alone: How Culture Transformed Human Evolution, Chicago: University of Chicago Press.

Sachs, E. (1992), The Development Dictionary, London: Zed Books.

Sahal D. (1981), “Alternative Conceptions of Technology”, Research Policy 10(1): 2-24.

Sahlins D. ([1976] 1982), Uso y abuso de la biología. Una crítica antropológica de la sociobiología, Madrid: Siglo XXI.

Shiva, V. (1995), "Globalism, Biodiversity and the Third World”, en Goldsmith, E., Khor, M., Norberg-Hodge, H. y V. Shiva (eds.), The Future of the Progress, Guildford, UK: Green Books and The International Society for Ecology and Culture, pp. 50-67.

Simondon, G. (2007), El modo de existencia de los objetos técnicos, Buenos Aires: Prometeo.

Wilson, E.O. (1975), Sociobiology: The New Synthesis, Cambridge: Belknap/Harvard University Press.

Wilson, E.O. (1998), Consilience. The Unity of Knowledge, New York: Alfred A. Knopf.

Wilson, E.O. ([1978] 2004), On Human Nature, Cambridge: Harvard University Press. 